\title{
Temperature dependent survival and fecundity of Lepidelphax pistiae Remes Lenicov (Hemiptera: Delphacidae), a potential biological control agent of Pistia stratiotes L. (Araceae)
}

Ashley B. C. Goode (i) ${ }^{a}$, Carey R. Minteer ${ }^{b}$, Philip W. Tipping ${ }^{a}$, Eileen Pokorny ${ }^{a}$, Ryann J. Valmonte ${ }^{\mathrm{a}, \mathrm{d}}$, Jeremiah R. Foley ${ }^{\mathrm{c}}$ and Brittany K. Knowles ${ }^{\mathrm{a}}$

aUSDA-ARS Invasive Plant Research Laboratory (IPRL), Ft. Lauderdale, FL, USA; ${ }^{\mathrm{b}}$ Indian River Research and Education Center, University of Florida, Fort Pierce, FL, USA; 'Department of Entomology, Virginia Polytechnic Institute and State University, Blacksburg, VA, USA; ${ }^{d}$ Department of Materials Science and Engineering, University of Central Florida, Orlando, FL, USA

\begin{abstract}
Lepidelphax pistiae Remes Lenicov (Hemiptera: Delphacidae) is monophagous on Pistia stratiotes L. (Araceae), an invasive floating plant in Florida. Temperature studies were conducted to determine the optimal temperature for development and reproduction for this potential biological control agent. Egg development time decreased as temperature increased from $17^{\circ} \mathrm{C}$ to $30^{\circ} \mathrm{C}$. No eggs developed and no nymphs survived at $15^{\circ} \mathrm{C}$. Adult females survived the longest at $15^{\circ} \mathrm{C}$, indicating that they might be more resilient to cold temperatures. Optimal temperature for nymph development was $25^{\circ} \mathrm{C}$ with $29 \%$ surviving to adulthood in $18.2 \pm 0.4$ days.
\end{abstract}

\section{ARTICLE HISTORY}

Received 16 September 2019

Returned 31 December 2019

Accepted 11 December 2019

\section{KEYWORDS}

Delphacid; planthopper;

insect development;

reproductive rate

Lepidelphax pistiae Remes Lenicov (Hemiptera: Delphacidae) was described in 2013 from specimens collected in northern and central Argentina (Remes Lenicov \& Walsh, 2013). After an initial host range test indicated that it was likely specific to Pistia stratiotes L. (Araceae), an invasive floating plant in Florida (Cabrera Walsh, Maestro, Sosa, \& Tipping, 2014), it was imported into quarantine at the USDA-ARS Invasive Plant Research Laboratory (IPRL) in Fort Lauderdale, FL, for evaluation as a potential biocontrol agent. Additional host range and impact studies confirmed that this species is indeed specific and damaging to P. stratiotes (Goode et al., 2019; Remes Lenicov, Defea, Rusconi, \& Cabrera Walsh, 2017).

Determining an insect's thermal requirements is essential to optimising its mass rearing, establishing it in the adventive range, and predicting its rate and range of dispersal (May \& Coetzee, 2013; Remes Lenicov et al., 2017). Accordingly, L. pistiae was tested in a range of constant temperatures to determine the development time of eggs and nymphs, and the longevity and fecundity of adult females. Lepidelphax pistiae has been kept in colony in a quarantine greenhouse at IPRL since 2013 where it has been reared on P. stratiotes fertilised with water soluble fertiliser (Peters Professional 24-8-16 Fertilizer,

CONTACT Ashley B. C. Goode ashley.goode@ars.usda.gov E USDA-ARS Invasive Plant Research Laboratory (IPRL), 3225 College Ave., Ft. Lauderdale, FL 33314, USA

(C) 2020 Informa UK Limited, trading as Taylor \& Francis Group 
Everris, Geldermalsen, Netherlands) at a rate of $1 \mathrm{~g} / 5 \mathrm{~L}$ deionised water and kept under natural light conditions, ambient temperatures $\left(18-32^{\circ} \mathrm{C}\right)$, and $70-85 \% \mathrm{RH}$ in the greenhouse year round.

This temperature study was conducted between 2015 and 2019. Trials were conducted concurrently in two environmental chambers (Model E36L, Percival Scientific, Perry IA) for each life stage at each temperature, with ten samples per chamber. Each temperature was repeated at least twice, however some were repeated additional times due to high mortality and loss of individuals. Chambers had a photoperiod of $12 \mathrm{~L}: 12 \mathrm{D}$ and were set to maintain a constant temperature $\left(15^{\circ} \mathrm{C}, 20^{\circ} \mathrm{C}, 25^{\circ} \mathrm{C}\right.$, or $\left.30^{\circ} \mathrm{C}\right)$. Additionally, $17^{\circ} \mathrm{C}$ was tested for eggs only as a tentative threshold for development. Pistia stratiotes survives at temperatures of $15-35^{\circ} \mathrm{C}$ (Neuenschwander, Julien, Center, \& Hill, 2009), so these experiments were within reasonable temperatures for this plant species. Temperature sensors (Thermochron iButton DS1921G-F5, Maxim/Dallas iButton Products, San Jose, CA) were kept in all chambers during all trials to monitor and confirm temperature within each chamber. Each sample contained a single $P$. stratiotes rosette placed in a cylindrical $490.3 \mathrm{~cm}^{3}$ polystyrene dish, $6.5 \mathrm{~cm}$ in height, with a friction fitting lid. An area of $35.3 \mathrm{~cm}^{2}$ of each lid was screened with chiffon fabric. Water fertilised as above was added initially and as needed through the screened lid to minimise disturbance and prevent insect escape.

In the egg development experiment, a parental cohort consisting of three 1-to- $2 \mathrm{w}$ old adults $\left(20^{*}: 1\right.$ ) $)$ was placed on the plants in the containers for $24 \mathrm{~h}$ and then removed. Plants were monitored twice daily for $F_{1}$ nymph emergence which was recorded, and the nymphs removed as they appeared. The experiment ended once no new nymphs emerged for two consecutive days.

For the nymphal development experiment, a single first or second instar was carefully placed on the plant. These first instars had been collected within $24 \mathrm{~h}$ of emergence while second instars were collected within $24 \mathrm{~h}$ of the first molt (as indicated by exuviae). Initially, second instars were used because first instars are very delicate and are easily injured, but once a successful protocol was developed for transferring first instars safely, they were then used for all subsequent tests. The samples were then monitored twice daily until the nymphs molted into adults or died. The dates when exuviae appeared were recorded and then removed.

The adult experiment examined female fecundity and longevity using newly molted adults $(20: 1$ o $)$ that were placed onto plants in the screened containers. The adults were moved every seven days to new plants in new containers and any mortality was recorded. If a male died, they were not replaced. The adult portion of the experiment ended with the death of the female in each sample group. The previously exposed plants were monitored for emergence of $F_{1}$ nymphs, which were counted and removed as they appeared. Previously exposed plants were discarded after no nymphs emerged for two consecutive days or after 30 days if no emergence was observed.

Data were tested for normality and equality of variances using the Shapiro-Wilk test and Levene's test in R (R Core Team, 2019). Egg, nymph, and adult data were not normally distributed and could not be successfully transformed, so the non-parametric KruskalWallis test was used to evaluate differences among temperature treatments, and posthoc pairwise comparisons were conducted using the Wilcoxon rank sum test with a Bonferroni correction. Generalised additive models were used to analyze egg and adult data only, as nymph data were limited. 
The number of days from the time the parental cohort was added to the sample container to emergence of $\mathrm{F}_{1}$ first instars was influenced by temperature $\left(\chi^{2}=82.3, \mathrm{~d} f=3, p<\right.$ $0.001)$ but not chamber $\left(\chi^{2}=3.48, \mathrm{~d} f=1, p=0.06\right)$. The pairwise Wilcoxon sign rank test indicated that development time differed significantly between temperatures (all $p<<$ 0.001 ) and the time to emergence decreased as temperature increased (Table 1). The generalised additive model found that both the intercept and temperature variable were significant $\left(p<<0.001\right.$, adj. $\left.R^{2}=0.86\right)$, resulting in the following equation predicting the number of days spent in the egg stage:

$$
\text { Days }=(-1.1 * \text { Temperature })+40.4
$$

Development times for all instars were influenced by temperature $\left(\chi^{2}=8.7-59.3\right.$, all $p<$ 0.05 ), with $25^{\circ} \mathrm{C}$ having the shortest duration for all stages (Table 1). Only fourth instar duration was affected by chamber $\left(\chi^{2}=4.40, \mathrm{~d} f=1, p=0.04\right)$. Post-hoc tests could not be done on nymphs because of their overall low survival. For example, no nymphs developed at $15^{\circ} \mathrm{C}$ and only one nymph survived to adulthood at $30^{\circ} \mathrm{C}$. Although first instar nymphs kept at $20^{\circ} \mathrm{C}$ had the highest survival rates initially (76\% survival to second instar), more nymphs reached the adult stage at $25^{\circ} \mathrm{C}$, with $29 \%$ developing into adults compared to $25 \%$ at $20^{\circ} \mathrm{C}$.

Adult female longevity, fecundity, and the number of nymphs emerged per week were influenced primarily by temperature and secondarily by chamber (Table 2). The effect of the environmental chamber was significant in this particular set of experiments because a third chamber was added for one trial at $15^{\circ} \mathrm{C}$ and one at $20^{\circ} \mathrm{C}$, but not for any other temperatures. Temperatures always vary slightly among chambers, but all averaged $\leq \pm 1.4^{\circ} \mathrm{C}$ from the target temperature in this experiment.

Although adults survived longest at $15^{\circ} \mathrm{C}(3.6 \pm 0.3$ weeks, pairwise Wilcoxon sign rank text with Bonferroni correction for $15^{\circ} \mathrm{C}$ versus $25^{\circ} \mathrm{C}$ and $30^{\circ} \mathrm{C}: p<0.01$ ), no nymphs

Table 1. Mean ( \pm SE) duration (days) of each life stage, percent survival of nymphs, and reproductive rate and longevity (weeks) of females in temperature studies. While each trial was started with 20 samples, due to non-experimental mortality and loss of individuals, the number reported and used for analysis was generally less than what was started initially.

\begin{tabular}{|c|c|c|c|c|c|c|}
\hline Life Stage & Variable & $15^{\circ} \mathrm{C}$ & $17^{\circ} \mathrm{C}$ & $20^{\circ} \mathrm{C}$ & $25^{\circ} \mathrm{C}$ & $30^{\circ} \mathrm{C}$ \\
\hline Eggs & Duration & 0 & $23.53 \pm 0.31$ & $17.69 \pm 0.57$ & $10.65 \pm 0.22$ & $8.40 \pm 0.17$ \\
\hline Nymphs & $\mathrm{N}$ & 50 & & 80 & 68 & 60 \\
\hline \multirow[t]{2}{*}{ 1st Instar } & Duration & $15^{*}$ & & $7.87 \pm 0.37$ & $3.76 \pm 0.24$ & $6.15 \pm 0.63$ \\
\hline & Survival & $2^{*}$ & & $76 \pm 0.05$ & $72 \pm 0.05$ & $33 \pm 0.06$ \\
\hline \multirow[t]{2}{*}{ 2nd Instar } & Duration & 0 & & $5.53 \pm 0.28$ & $3.60 \pm 0.27$ & $5.09 \pm 0.45$ \\
\hline & Survival & 0 & & $64 \pm 0.05$ & $51 \pm 0.06$ & $18 \pm 0.05$ \\
\hline \multirow[t]{2}{*}{ 3rd Instar } & Duration & 0 & & $6.29 \pm 0.38$ & $3.65 \pm 0.32$ & $4.57 \pm 0.52$ \\
\hline & Survival & 0 & & $51 \pm 0.06$ & $38 \pm 0.06$ & $12 \pm 0.04$ \\
\hline \multirow[t]{2}{*}{ 4th Instar } & Duration & 0 & & $6.11 \pm 0.47$ & $3.76 \pm 0.25$ & $6.80 \pm 0.95$ \\
\hline & Survival & 0 & & $34 \pm 0.05$ & $25 \pm 0.05$ & $8 \pm 0.04$ \\
\hline \multirow{2}{*}{ 5th Instar } & Duration & 0 & & $6.87 \pm 0.77$ & $4.27 \pm 0.27$ & $7^{*}$ \\
\hline & Survival & 0 & & $19 \pm 0.04$ & $22 \pm 0.05$ & $2^{*}$ \\
\hline \multirow[t]{2}{*}{ Total Nymph } & Duration & 0 & & $32.30 \pm 0.54$ & $18.25 \pm 0.45$ & $22^{*}$ \\
\hline & Survival & 0 & & $25 \pm 0.05$ & $29 \pm 0.06$ & $2^{*}$ \\
\hline \multirow[t]{4}{*}{ Adult Female } & $\mathrm{N}$ & 40 & & 45 & 84 & 60 \\
\hline & Longevity & $3.6 \pm 0.33$ & & $2.82 \pm 0.32$ & $2.32 \pm 0.15$ & $1.23 \pm 0.09$ \\
\hline & Reproductive rate & 0 & & $53.76 \pm 8.87$ & $88.46 \pm 9.11$ & $15.4 \pm 2.59$ \\
\hline & Nymphs/Week & 0 & & $14.81 \pm 2.31$ & $34.65 \pm 3.33$ & $10.52 \pm 2.15$ \\
\hline
\end{tabular}

${ }^{*}$ Only one nymph survived, so only one value is given. Only eggs were tested at $17^{\circ} \mathrm{C}$. 
Table 2. Kruskal-Wallis rank sum test of adult female longevity, total number of nymphs, and number of nymphs per week.

\begin{tabular}{llccc}
\hline & Variable & $\chi^{2}$ & $\mathrm{~d} f$ & $p$ \\
\hline Temperature & \% Longevity & 45.31 & 3 & $<0.001$ \\
& Total Nymphs & 74.52 & 3 & $<0.001$ \\
Chamber & Nymphs/Week & 69.95 & 3 & $<0.001$ \\
& o Longevity & 5.31 & 2 & 0.07 \\
& Total Nymphs & 9.32 & 2 & 0.009 \\
& Nymphs/Week & 12.76 & 2 & 0.002 \\
\hline
\end{tabular}

emerged at that temperature in this test or in the egg test. Longevity decreased as the temperature increased with females kept at $30^{\circ} \mathrm{C}$ having the shortest lifespan $(1.23 \pm 0.09$ weeks, pairwise Wilcoxon sign rank text with Bonferroni correction for $30^{\circ} \mathrm{C}$ versus all other temperatures: $p<0.01)$. At $30^{\circ} \mathrm{C}, 31.6 \%$ of adult females did not survive past one week and of those that did, $41.4 \%$ did not produce any offspring at all. In this experiment, plants deteriorated faster at higher temperatures, but all plants were still alive and floating at the end of each experiment.

Generalised additive models found both the intercept and temperature variable significant $\left(p<<0.001\right.$, adj. $R^{2}=0.145$ ) for female longevity resulting in the equation:

$$
\text { Female longevity }(\text { weeks })=(-0.16 * \text { Temperature })+6.2
$$

Females at $15^{\circ} \mathrm{C}$ and $30^{\circ} \mathrm{C}$ produced significantly fewer total nymphs than the females at $20^{\circ} \mathrm{C}$ and $25^{\circ} \mathrm{C}$ (pairwise Wilcoxon sign rank text with Bonferroni correction for $15^{\circ} \mathrm{C}$ versus all other temperatures: $p<<0.001$; pairwise Wilcoxon sign rank text with Bonferroni correction for $30^{\circ} \mathrm{C}$ versus all other temperatures: $\left.p<0.01\right)$. Nymph emergence per week was similar at $20^{\circ} \mathrm{C}$ and $30^{\circ} \mathrm{C}$ (Table 1). However, because of the shorter female lifespan at $30^{\circ} \mathrm{C}$, fewer total nymphs were produced. Females kept at $25^{\circ} \mathrm{C}$ produced more nymphs per week than those kept at other temperatures (pairwise Wilcoxon sign rank text with Bonferroni correction for $25^{\circ} \mathrm{C}$ versus $20^{\circ} \mathrm{C}$ and $30^{\circ} \mathrm{C}: p<0.05$ ) and they also had a comparable life span to those kept at $20^{\circ} \mathrm{C}$. Overall, the data suggest that, with shorter development time for nymphs, $25^{\circ} \mathrm{C}$ would be the optimal temperature for mass production of this insect.

In the model for the nymphs emerged per week only the intercept was significant ( $p=$ 0.003 , adj. $R^{2}=0.005$ ) indicating that temperature did not predict this variable well despite significant differences using Kruskal-Wallis testing. One possible explanation is unaccounted variation in female age that was less responsive to temperature. Female longevity and nymphs emerged per week are both variables that influence total number of nymphs produced. In the model for total nymphs produced, neither variable alone was significant ( $p=0.76$ and $p=0.65$, respectively) but the model was highly predictive (adj. $R^{2}=0.99$ ) because of the interaction factor of the two $(p<<0.001)$ :

$$
\text { Total nymphs produced }=0.99 * \text { Nymphs per week } * \text { Female longevity }
$$

The optimal temperature of $25^{\circ} \mathrm{C}$ for development found in this study aligns with other Delphacid species, including Peregrinus maidis (Ashmead) (Hemiptera: Delphacidae), whose optimal development temperatures are between $21.1^{\circ} \mathrm{C}$ and $26.7^{\circ} \mathrm{C}$ (Tsai \& Wilson, 1986) and Nilaparvata lugens (Stål) (Hemiptera: Delphacidae) whose optimal development temperatures are $25-30^{\circ} \mathrm{C}$ (Krishnaiah et al., 2005). In Megamelus scutellaris 
Berg (Hemiptera: Delphacidae), which is native to the same region as L. pistiae, the optimal temperature for instar development was also $25^{\circ} \mathrm{C}$ (May \& Coetzee, 2013). Similar to L. pistiae, M. scutellaris egg development time also decreases with increased temperature, but at the highest tested temperature $\left(30^{\circ} \mathrm{C}\right)$ 1st instars do not survive (May \& Coetzee, 2013).

The limited survival of $L$. pistiae females at the highest temperature tested, $30^{\circ} \mathrm{C}$, in conjunction with the longer lifespan at $15^{\circ} \mathrm{C}$ is a pattern seen in other Delphacid species. Peregrinus maidis can survive $96.6 \pm 15.6$ days and 107.6 \pm 6.2 days for males and females, respectively, at $15.6^{\circ} \mathrm{C}$ but only $10-20 \%$ as long at $32.2^{\circ} \mathrm{C}$ (Tsai \& Wilson, 1986). Nilaparvata lugens also has a longer adult lifespan at cooler temperatures, 19.6 \pm 0.7 days at $15^{\circ} \mathrm{C}$ and $30.0 \pm 1.1$ days at $20^{\circ} \mathrm{C}$, but only one half to one third as long at higher temperatures. The trend towards increased reproductive rate at higher temperatures with sharp declines as the maximum threshold is reached also occurs in N. lugens (Krishnaiah et al., 2005).

Evaluating insect responses to constant temperature may not be predictive of the continuum of $L$. pistiae responses to environmental conditions in Florida but it does provide broad guidance and prediction of the natural history of this species, namely, that the shortest development time, the highest nymph survival rate, and the most nymphs produced per female per week should occur at $25^{\circ} \mathrm{C}$. These experiments also predict that adults could persist up to a month or more through colder conditions, but require at least temperatures of $17^{\circ} \mathrm{C}$ for eggs to develop. Any mass production regimen for this species should include a higher temperature setting for egg development along with lower temperatures for nymph development and adult reproduction. This information can also be used to inform other biocontrol activities, including climate matching of potential release locations, modelling of establishment and dispersal, and integration into existing pest management programmes.

\section{Acknowledgements}

The authors thank Yuichi Shinno at the Invasive Plant Research Laboratory for his assistance with the experiment. Mention of trade names or commercial products in this publication is solely for the purpose of providing specific information and does not imply recommendation or endorsement by the U.S. Department of Agriculture (USDA).

\section{Disclosure statement}

No potential conflict of interest was reported by the authors.

\section{ORCID}

Ashley B. C. Goode (D) http://orcid.org/0000-0001-6515-3954

\section{References}

Cabrera Walsh, G., Maestro, M., Sosa, A., \& Tipping, P. W. (2014). Specificity of Lepidelphax pistiae (Hemiptera: Delphacidae) to Pistia stratiotes (Araceae). Biocontrol Science and Technology, 24(4), 485-488. doi:10.1080/09583157.2013.867012 
Goode, A. B., Minteer, C. R., Foley, J. R., Tipping, P. W., Valmonte, R. J., Knowles, B. K., \& Gettys, L. A. (2019). Host range of Lepidelphax pistiae (Hemiptera: Delphacidae) and its potential impact on Pistia stratiotes L. (Araceae). Biocontrol Science and Technology, 29(7), 706-714. doi:10.1080/ 09583157.2019.1587738

Krishnaiah, N. V., Rama Prasad, A. S., Rao, C. R., Pasalu, I. C., Jhansi Lakshmi, V., Lakshmi Narayana, V., \& Lingaiah, T. (2005). Effect of constant and variable temperatures on biological parameters of rice Brown Planthopper, Nilaparvata lugens (Stål). Indian Journal of Plant Protection, 33(2), 181-187.

May, B., \& Coetzee, J. (2013). Comparisons of the thermal physiology of water hyacinth biological control agents: Predicting establishment and distribution pre-and post-release. Entomologia Experimentalis et Applicata, 147(3), 241-250. doi:10.1111/eea.12062

Neuenschwander, P., Julien, M. H., Center, T. D., \& Hill, M. P. (2009). Pistia stratiotes L. (Araceae). In Biological control of tropical weeds using arthropods (pp. 3323-3352). New York, NY: Cambridge University Press.

R Core Team. (2019). R: A language and environment for statistical computing. Vienna, Austria: R Foundation for Statistical Computing. Retrieved from https://www.R-project.org/

Remes Lenicov, A. M. M., Defea, B., Rusconi, J., \& Cabrera Walsh, G. (2017). Studies on the immature stages of the planthopper Lepidelphax pistiae (Hemiptera: Delphacidae), a potential biocontrol agent for the aquatic weed Pistia stratiotes (Araceae) from Argentina. Austral Entomology, 56 (4), 384-391. doi:10.1111/aen.12248

Remes Lenicov, A. M. M., \& Walsh, G. C. (2013). A new genus and species of Delphacini (Hemiptera: Fulgoromorpha: Delphacidae) associated with hydrophytic plants in Argentina. Florida Entomologist, 96(4), 1350-1358. doi:10.1653/024.096.0414

Tsai, J. H., \& Wilson, S. W. (1986). Biology of Peregrinus maidis with descriptions of immature stages (Homoptera: Delphacidae). Annals of the Entomological Society of America, 79(3), 395401. doi:10.1093/aesa/79.3.395 